\title{
eLyra
}

\section{As fotografias verbais de Blaise Cendrars}

\author{
Natalia Aparecida Bisio de Araujo \\ Universidade Estadual Paulista
}

Resumo: O presente artigo tem como objetivo a análise da obra Documentaires, de Blaise Cendrars, a fim de se refletir como o texto promoveu uma recriação do romance Le Misterieux Docteur Cornélius, de Gustave Le Rouge, inserindo trechos de $\mathrm{Au}$ Congo Belge, de Maurice Calmeyn. O poeta utilizou o processo denominado "fotografias verbais", que se aproximava da montagem cinematográfica e da fotografia. Os Documentaires fazem parte do projeto estético vanguardista de Cendrars, que sempre buscou diversas formas de inovar o gênero e situá-lo no mundo moderno do início do século XX. Assim, contextualizaremos os princípios teóricos que regiam os movimentos vanguardistas em geral e a obra poética de Blaise Cendrars. Posteriormente, faremos uma análise de Documentaires, inserindo o texto no projeto estético do poeta franco-suíço e observando a forma como o escritor faz um trabalho de recriação de outros textos partindo de estudos da intertextualidade.

Palavras-chave: Blaise Cendrars, Vanguardas Europeias, Documentaires, Fotografias verbais

\begin{abstract}
This paper aims to analyze the Documentaires by Blaise Cendrars, in order to reflect how the text promoted a re-creation of the novel Le Misterieux Docteur Cornélius by Gustave Le Rouge, inserting excerpts from Au Congo Belge by Maurice Calmeyn. The poet used the process called "verbal photographs", which approached the cinematographic montage and photography. The Documentaires are part of the avant-garde design by Cendrars, who always sought different ways to innovate the genre and situate it in the modern world of the early twentieth century. Thus, we will contextualize the theoretical principles that governed the avantgarde movements in general and in the poetic work of Blaise Cendrars. Later, we will do an analysis of
\end{abstract}


Documentaires, inserting the text into the aesthetic project of the Franco-Swiss poet and observing how the writer does a work of re-creation of other texts starting from studies of intertextuality.

Keywords: Blaise Cendrars, European avant-garde, Documentaires, Verbal photographs

A Vanguarda se consolidou como uma das forças antagonistas que surgiram no início do século XX, não somente frente à tradição literária, mas também em oposição ao domínio político e social. Com esse papel assumido, os movimentos vanguardistas ficaram conhecidos por um espírito de negação, que se deu por meio de uma estratégia radical: impor-se por meio de uma retórica agressiva e de destruição. $O$ ato de rejeição mais destacável da vanguarda é o rompimento com a tradição.

A negação da tradição é mais uma necessidade de se transgredirem os limites da arte como instituição, do que um ataque direto a qualquer escola literária anterior. Peter Bürger (1993) defende que os movimentos vanguardistas promovem em suas discussões estéticas uma crítica do próprio sistema de produção artístico, ditado pela tradição, que ataca a "instituição arte", ou seja, "tanto o aparelho de produção e distribuição da arte quanto às ideias dominantes em arte numa época dada e que determinam essencialmente a recepção das obras" (Bürger 1993: 52).

Na poesia, a Vanguarda lutou pela "liberdade" e anulação das restrições impostas pelas antigas normas, visando à desconstrução de um sistema estético de escritura fundado na tradição e na razão, que desmistificou a linguagem literária. Nesse sentido, pode-se dizer que os movimentos vanguardistas criaram certo apreço pela poesia, pois a viam como uma grande ferramenta de se atingir o novo e o libertário, já que o gênero é capaz de se reinventar todo o tempo. De acordo com Weisgerber, a poesia era apreciada como "une possibilité permanente d'ouverture, une 'forme' (vide) d'esprit pouvant se remplir différemment à tout instant" (Weisgerber 1986: 705) [[...] uma possibilidade permanente de abertura, uma 'forma' (vazia) de espírito que pode se preencher de modos diferentes a todo instante]. Outros críticos também afirmam o mesmo, como Compagnon (2003: 44) que 
reconhece a poesia como a grande representação da modernidade em literatura, sendo o gênero que abandonou progressivamente as formas tradicionais.

Além de suas possibilidades de inovação, os vanguardistas também queriam recuperar a verdadeira essência da poesia e refletir, por meio dela, o espírito da novidade vivido pelo início do século $\mathrm{XX}$, tanto pelas novas descobertas científicas, quanto pelos grandes avanços tecnológicos. Para revelar o "novo" vivido pelo mundo, os vanguardistas renovariam não somente aspectos estruturais da poesia - como os princípios formais do verso, da estrofe, da imagem, dentre outros - mas atingiria também a essência da lírica: buscava-se a purificação do gênero ou sua redução ao essencial.

A purificação da poesia chegou a ponto de modificar mesmo a essência do gênero: se antes a poesia estava nos versos, estrofes e rimas, agora ela "reside virtuellement en toutes choses" (Weisgerber 1986: 734) [[...] reside virtualmente em todas as coisas], inclusive em outros gêneros artísticos, como na prosa e na pintura; é fantasia e imaginação; a poesia é, por fim, uma maneira de viver, uma atividade do espírito ou uma forma de ação mediante a vida, conforme afirma Blaise Cendrars: "Toute vie n'est qu'un poème, un mouvement" (Cendrars 1987: 99) [Toda a vida é um poema, um movimento].

Com essa tentativa de se purificar a poesia, a vanguarda uniu-a de forma indissociável às outras artes, como a pintura, a música, a dança, o cinema e a fotografia. Segundo Weisgerber (1986), a junção da poesia e dos outros gêneros demonstrava "leur volonté de sauter les barrières des langues et des genres [...]. Abattre les cloisons pour embrasser l'univers entier, pour se fondre dans le grand tout" (idem: 942) [[...] sua vontade de pular as barreiras das línguas e dos gêneros [...]. Derrubar as paredes para abraçar o universo inteiro, para fundir-se no grande todo [...]].

Além dessas questões, segundo a vanguarda, o ato de criação poética também se revela autônomo, ou seja, cada obra desenvolve-se segundo suas próprias leis e suas próprias especificidades para a constituição dos meios de expressão (idem: 757). Conforme explica Tzara, esse processo autônomo significava "donner à chaque élément son intégrité, son autonomie, condition nécessaire à la création de nouvelles constellations." (Tzara apud Weisgerber 1986: 757) [dar a cada elemento sua integridade, sua autonomia, condição 
necessária para a criação de novas constelações]. Ter liberdade e autonomia significa que cada poema possui uma vida independente: cria sua realidade e forma própria, única.

A espontaneidade no ato de criação da poesia revelou novos princípios formais muito interessantes como a valorização do espaço da página e da tipografia; a colagem ou montagem; a mistura do lírico com outros gêneros artísticos, e uma série de outros elementos. Assim, cada poema tornava-se uma experiência única e inovadora.

É nesse contexto de inovação, de liberdade e de experimentação que se inseriu toda a obra do poeta Blaise Cendrars. Nascido em Chaux-de-Fonds na Suíça (1887) e registrado com o nome de Frédéric-Louis Sauser, o pseudônimo criado pelo artista significa "brasa" e "cinzas" - "Blaise" vem de "braise" (brasa) e "Cendrars", de "cendres" (borralho). Foi no "fogo" das artes modernas de vanguarda que o escritor inseriu sua obra poética, sempre repleta de grandes inovações formais e das experiências que Cendrars colheu no mundo moderno, em suas inúmeras viagens por vários países. O escritor faz uma poesia que, em muitos aspectos, desvinculou-se da tradição e ligou-se à estética das vanguardas. Com o uso dessas técnicas, que são muito comuns em toda a sua poesia, cada obra possui uma singularidade no uso de tais recursos vanguardistas.

Enquanto as vanguardas possuíam uma atitude radical de busca pelo novo e de rompimento com a tradição, chamando a atenção de artistas e do público por meio de uma retórica espalhafatosa de destruição, Cendrars também ficou conhecido por criar grandes conflitos no meio literário da sua época. ${ }^{1}$ Dentre as obras controversas e inovadoras de Cendrars está Kodak, publicada em Stock, na coleção "Poésies du temps", em 1924. Esse título já ilustra o grande interesse de Cendrars pelas novas tecnologias de sua contemporaneidade. A empresa foi uma das responsáveis pela popularização de máquinas fotográficas para amadores, diminuindo o tamanho das câmeras e ampliando as formas como as imagens eram exibidas. A Kodak também teve um importante papel no desenvolvimento do cinema.

A publicação do livro é acompanhada por uma polêmica: a empresa de produtos fotográficos, homônima ao livro de Cendrars, se opôs ao emprego do título e exigiu que ele fosse mudado nas próximas edições. Por conta desse contratempo, o poeta decide 
renomear o livro com o subtítulo da primeira impressão: Documentaires. Em carta aos editores de Stock, Cendrars comenta o ocorrido:

Pauvres poètes, travaillons. Qu'importe un titre. La poésie n'est pas dans un titre mais dans un fait, et comme en fait ces poèmes, que j'ai conçus comme des photographies verbales, forment un documentaire, je les intitulerai dorénavant DOCUMENTAIRES. Leur ancien sous-titre. C'est peut-être aujourd'hui un genre nouveau. (Cendrars 2006: 384; grifos do autor)

[Pobres poetas, trabalhemos. Pouco importa um título. A poesia não está em um título, mas em um fato, e como na realidade esses poemas, que eu concebi como fotografias verbais, formam um documentário, eu as intitulei doravante DOCUMENTÁRIOS. Seu antigo subtítulo. Hoje talvez um gênero novo].

Já nascida sob o estigma polêmico, que já circulava o espírito de toda a obra vanguardista de Cendrars, o poeta agora declara ter criado um "novo gênero". Esse gênero inovador de Documentaires se liga ao termo "fotografias verbais", que possui diversos sentidos. Além de se relacionar com o primeiro título da obra - a empresa fotográfica Kodak -, os poemas de Documentaires apresentam, em seu estilo prosaico, descrições minuciosas das paisagens e dos personagens suscitados pelos versos. Se a fotografia capta uma cópia fiel de uma cena ou de um objeto em um clique, as "fotografias verbais" seriam esse mesmo tipo de reprodução, não por meio da câmera, mas por meio da linguagem. Assim, o gênero poético busca se aproximar da fotografia. Em entrevista, Cendrars afirma: "[les photographies verbales viennent] de ce que j'avais sous les yeux, de ce que je pensais, de ce que je devinais, du verbe" (Cendrars 2006: 19) [[...] [as fotografias verbais advêm] daquilo que que eu tinha sob os olhos, daquilo que eu pensava, daquilo que eu adivinhava, do verbo]. Desse modo, o poeta procura fazer um verdadeiro álbum de suas viagens pela América do Norte, mais especificamente dos Estados Unidos e do Canadá, e pela África, descrevendo as características de suas paisagens, de sua cultura e de seu povo.

Ao documentar as informações colhidas na América do Norte, o poeta aponta com entusiasmo a modernidade vivida por seu tempo, sobretudo aquela apresentada na figura das máquinas, tão apreciadas pelos futuristas. Se o Novo Mundo ainda continha aquele exotismo identificado pelos viajantes europeus dos séculos XVI ao XIX, principalmente por 
suas paisagens paradisíacas e pela riqueza e diversidade de sua fauna, o continente também demonstrava grande modernização e não deixava de provar do mesmo progresso que a Europa já experimentava. Cendrars demonstrará, assim, as duas faces da América do Norte: o mundo natural e o mundo modernizado. Em "Campagne", por exemplo, o poeta descreve a "magnífica paisagem" do Canadá, com suas imensas florestas e áreas praticamente desertas:

Paysage magnifique

Verdoyantes forêts de sapins de hêtres de châtaigniers coupées de florissantes cultures de blé d'avoine

[de sarrasin de chanvre

Tout respire l'abondance

Le pays d'ailleurs est absolument désert

À peine rencontre-t-on par-ci par-là un paysan conduisant une charrette de fourrage

Dans le lointain les bouleaux sont comme des colonnes d'argent (Cendrars 2006: 169-170)

[Paisagem magnífica

Verdejantes florestas de abetos de faias de castanheiros entrecortadas por florescentes culturas de [trigo de aveia de trigo-sarraceno de cânhamo

Tudo respira a abundância

O país aliás é absolutamente deserto

Quando muito encontram-se por aqui por ali um camponês conduzindo uma charrete de forragem Ao longe as bétulas são como colunas de prata].

Porém, ao mesmo tempo em que o poeta fala de regiões ainda pouco habitadas e dominadas pela natureza exuberante, Cendrars também apresenta vários aspectos de modernidade e urbanização vividos pelo Novo Mundo. No poema "Office", o poeta enumera todo o maquinário, altamente moderno, presente em um escritório:

Radiateurs et ventilateurs à air liquide

Douze téléphones et cinq postes de T.S.F.

D’admirables classeurs électriques contiennent les myriades de dossiers industriels et scientifiques sur [les affaires les plus variées [...]

Les larges verrières donnent sur le parc et la ville

Le soir les lampes à vapeur de mercure y répandent une douce lueur azurée. (idem: 149) 
[Radiadores e climatizadores

Doze telefones e cinco aparelhos receptores T.S.F.

Admiráveis arquivos elétricos que contêm miríades de dossiês industriais e científicos sobre os [assuntos mais variados $[\ldots]$

Os amplos vitrais dão para o parque e para a cidade

À noite as lâmpadas de vapor de mercúrio propagam no local uma suave luz azulada].

Dentre modernidade e exotismo, assim, o poeta faz seu documentário sobre a América do Norte. Ao procurar aproximar-se da fotografia, os poemas citados acima se mostram excessivamente descritivos, como se procurassem reproduzir a imagem do mundo real contemplada pelo poeta. Observa-se uma grande discrepância com o conceito de poesia ligado à tradição romântica, fundado no lirismo, na inspiração e na subjetividade, justamente pela objetividade ou quase despersonalização do "eu" em busca da reprodução "fiel" das imagens captadas. Ao fazer um inventário dos pertences modernos de um escritório e dispô-los em versos livres, sem rimas, enfim, de forma prosaica, as "fotografias verbais" de Cendrars contestam os moldes tradicionais da poesia.

Muitos anos depois da publicação de Documentaires, descobriram-se fatos surpreendentes sobre os poemas e constatou-se que a obra promovia outros recursos para a modernização do gênero poético. Em 1945, vinte anos após a publicação da obra, o poeta franco-suíço relata em Homme Foudroyé a lembrança de seu amigo Gustave Le Rouge, um escritor francês de romances populares, considerado por Cendrars "um poeta em seu domínio" de escrita. Após as reminiscências do amigo, ironicamente, o escritor de Documentaires revela que muitos de seus poemas foram "talhados a tesouradas" de uma obra do seu amigo. Com isso, o poeta faz uma declaração muito curiosa: "Avis aux chercheurs et aux curieux! Pour l'instant je ne puis pas dire davantage [...] à cause de l'éditeur qui serait mortifié d'apprendre avoir publié à son issue ma supercherie poétique" (Cendrars 1945: 186) [Aviso aos pesquisadores e curiosos! Por enquanto não posso dizer mais [...] por causa da editora que seria mortificada se soubesse que publicou a minha fraude poética].

Apesar do alerta aos estudiosos, é só vinte anos depois desse relato que Francis Lacassin descobre que 50 dos 63 poemas de Kodak foram tirados de Le Mystérieux Docteur Cornélius, de Le Rouge. O longo romance de três volumes baseava-se em uma história de 
aventura, mistério e ficção científica, que misturava o mundo moderno com o exotismo das paisagens naturais da América do Norte. Cendrars vale-se de excertos dessa obra, por meio de procedimentos como redução, enriquecimento, rearranjo, intercalação de trechos da obra (Leroy apud Cendrars 2006: 384). Inclusive os personagens que aparecem em Documentaires - Andrée, Frédérique, Dorypha, Milliardaire - são também retirados do livro de Le Rouge.

E as surpresas suscitadas pela obra não terminaram com a descoberta de Francis Lacassin. Em 1977, Yvette Bozon-Scalzitti constata que as seções "Fleuve" e "Chasse à l'éléphant", sobre as aventuras na África, foram também recortados de outra obra: o livro de viagens do caçador Maurice Calmeyn, Au Congo Belge, de 1912. São ao todo 13 poemas, que, somados aos 50 retirados de Le Mistérieux Docteur Cornélius, revelam que todos os poemas de Documentaires não foram originalmente escritos pelo poeta, mas retirados de excertos de outras obras. Segundo Claude Leroy (apud Cendrars 2006: 384), foi por conta dessas grandes descobertas que Documentaires ficou muito célebre em meio à crítica da época.

É evidente a semelhança do texto de Cendrars com as obras de Le Rouge e de Calmeyn. Primeiramente, segue um excerto de Le Mistérieux Docteur Cornélius que foi usado por Cendrars em Documentaires:

Vers la fin de l'année 190..., un groupe de capitalistes yankees avait décidé la fondation d'une ville, en plein Far West, au pied même des montagnes Rocheuses. Un mois ne s'était pas écoulé que la nouvelle cité, encore sans maisons, était déjà reliée par trois lignes au réseau ferré de l'Union. (Le Rouge 1992: 7)

[Por volta do fim do ano $190 \ldots$, um grupo de capitalistas yankees havia decidido fundar uma cidade, em pleno Far West, ao pé de montanhas Rochosas. Um mês ainda não havia passado quando a nova cidade, ainda sem casas, já estava ligada por três linhas à rede ferroviária da União].

Vers la fin de l'année 1911 un groupe de financiers yankees décide la fondation d'une ville en plein Far [West au pied des Montagnes Rocheuses Un mois ne s'est pas écoulé que la nouvelle cité encore sans aucune maison est déjà reliée par trois [lignes au réseau ferré de l’Union. (Cendrars 2006: 155) 
["Por volta do fim do ano 1911 um grupo de financistas yankees decidem fundar uma cidade em pleno [Far West ao pé de Montanhas Rochosas

Um mês ainda não passou e a nova cidade ainda sem nenhuma casa já está ligada por três linhas à [rede ferroviária da União]

\section{A mesma semelhança pode ser notada entre um excerto de Au Congo Belge e Documentaires, no poema "Fleuve":}

II n'y a pas de hautes herbes le long des rives, de grandes étendues de terres très basses se perdent au loin, des îles affleurent la surface de l'eau, de grands crocodiles se chauffent au soleil, nous en blessons plusieurs à balles expansives, mais ils parviennent à gagner le Nil. Des milliers de grands oiseaux couvrent les bancs de sable ou de boue. (Calmeyn 1921: 35)

[Não há capim alto ao longo das margens, as grandes extensões de terra muito baixas perdem-se ao longe, as ilhas nivelam a superfície da água, os grandes crocodilos se esquenta no sol, nós ferimos vários deles com balas expansivas, mas eles conseguiram alcançar o Nilo. Milhares de grandes aves cobrem os bancos de areia ou lama].

II n'y a pas de hautes herbes le long des rives

De grandes étendues de terres basses se perdent au loin

Des îles affleurent la surface de l'eau

De grands crocodiles se chauffent au soleil

Des milliers de grands oiseaux couvrent les bancs de sable ou de boue. (Cendrars 2006: 177)

[Não há capim alto ao longo das margens

As grandes extensões de terra muito baixas perdem-se ao longe

As ilhas nivelam a superfície da água

Os grandes crocodilos se esquenta no sol

Milhares de grandes aves cobrem os bancos de areia ou lama].

Desse modo, Cendrars, que já havia sido acusado de plagiário na ocasião da estreia do "Primeiro Livro Simultâneo", teria novamente se envolvido em outro caso de plágio? Como citado acima, em Homme Foudroyé, o próprio poeta comenta ter realizado uma "fraude poética". Porém, na verdade, o que o poeta franco-suíço faz é uma verdadeira recriação das obras de Le Rouge e Calmeyn. Ao constatar que Documentaires apropriou-se 
dos outros dois livros, aprimora-se o significado da expressão "fotografia do verbo", que qualificava o método de elaboração dos poemas: o escritor de Documentaires recria as obras de Le Rouge e Calmeyn quando "fotografa verbalmente" seus excertos e os transpõe para sua obra. Em O Trabalho da Citação, Antoine Compagnon afirma:

O trabalho da escritura é uma reescritura, visto que se trata de converter elementos separados e descontínuos num todo contínuo e coerente [...] Reescrever, realizar um texto a partir de seus fragmentos é arranjá-los ou associá-los, fazer as ligações ou as transições que se impõem entre os elementos presentes. Toda escritura é colagem e glosa, citação e comentário. (Compagnon 1996: 36)

Se qualquer trabalho de escrita já é uma forma de reescrita, os Documentaires de Cendrars o é mais ainda. O poeta retira fragmentos de outros textos e os recompõe, fazendo modificações e rearranjos que, por fim, criam uma obra completamente nova. O mais interessante aqui é que não se trata de um processo de intertextualidade por meio de uma menção ou de uma breve relação com uma obra anterior, mas de um verdadeiro processo de "reciclagem" de outros textos, que reaparecem como um produto novo.

Voltemos aos trechos de Documentaires confrontados com os excertos de Le Mistérieux Docteur Cornélius e Au Congo Belge. Na incrível semelhança entre eles, a ponto de parecerem ter sido copiados das obras "originais", Cendrars demostra seu princípio da fotografia, que procurou reproduzir uma cópia mais fiel possível dos excertos escolhidos. Porém, de acordo com o olhar do fotógrafo, essas imagens são reposicionadas de acordo com sua criatividade, sem seguir a linearidade estabelecida pelas obras de partida. 0 excerto da obra de Le Rouge citado acima, por exemplo, está exatamente no início de Le Mystérieux Docteur Cornélius; enquanto o trecho de Cendrars aparece no 14으 poema de Documentaires.

Além das modificações na ordem dos excertos "fotografados", pode-se notar outras alterações. Se compararmos o trecho citado acima de Calmeyn e seu corresponde em Documentaires, percebemos a supressão de algumas frases e palavras, não se tratando de uma escolha aleatória na retirada, mas de um verdadeiro processo de versificação: o trecho "colado" na obra de Cendrars apresenta uma evidente expressividade do estrato fônico pelas aliterações muito recorrente de oclusivas $/ \mathrm{d} /, / \mathrm{p} /, \mathrm{b} /, / \mathrm{g} /, \mathrm{c} / \mathrm{,} / \mathrm{t} /$, diretamente ligadas com as várias sibilantes $/ \mathrm{s} /, / \mathrm{s} /$, que contribuem para construção da imagem sonora 
do curso das águas obstruídos pelos "bancos de areia, de lama" ou ilhas cobertas de aves ou de crocodilos. O trecho suprimido do texto de partida - "nous en blessons plusieurs à balles expansives, mais ils parviennent à gagner le Nil" - quebraria a cadeia sonora gerada pelas aliterações.

No excerto acima comparado ao romance Le Mistérieux Docteur Cornélius, nota-se que a conjugação dos verbos nos versos de Cendrars aparecem no presente do indicativo, contrariamente à conjugação de Le Rouge, em outros tempos verbais. Já que Documentaires não se trata mais de um romance que desenvolve um enredo ficcional, mas de um "documentário" que descreve didaticamente um continente com a sua cultura, o seu povo e as suas paisagens, a conjugação no presente faz uma atualização dos fatos e aproxima o leitor ao momento da enunciação. Além disso, pode-se notar outra mudança muito significativa: a contextualização temporal da narrativa do romancista - "Vers la fin de l'année 190..." (Le Rouge 1992: 7) - é transposta para os poemas com uma data mais específica, 1911 - "Vers la fin de l'année 1911" (Cendrars 2006: 155). Enquanto Le Rouge situa temporalmente sua obra no século XX, sem mencionar o ano dos acontecimentos narrados, Cendrars, em sua atualização da obra, contextualiza-a exatamente no ano em que estava em viagem nos Estados Unidos. Dado que o poeta se insere como personagem da obra, essa data pode inferir que todas as descrições apresentadas em Documentaires são também relatos das viagens do escritor pelo continente Norte-Americano. Assim, Documentaires seria simultaneamente "fotografias" do romance de Le Rouge e "fotografias" das viagens de Cendrars, rompendo não só as fronteiras da questão da autoria, mas também aquelas entre prosa e poesia.

Outra característica da adaptação feita por Cendrars do texto de Le Rouge é a retirada da pontuação. O poeta aplica à obra todo o seu projeto estético que, muito próximo à ideia das palavras em liberdade e de todo projeto vanguardista, almejava a destruição das regras impostas à escrita poética, neste caso, o sistema ortográfico.

Algo muito interessante no trabalho das "fotografias verbais" realizadas por Cendrars é o fato de que, apesar da reorganização e reelaboração, os excertos retirados das duas obras de partida permaneceram muito semelhantes aos originais e passaram muitos anos sem ser reconhecidos. Talvez, só foram identificados pela dica do próprio Cendrars, que 
passou propositalmente anos esperando para fazer a revelação e pregar uma peça nos leitores e na crítica. Pensando nas questões relacionadas à intertextualidade, segundo Tiphaine Samoyault (2008: 9), cada texto constrói sua própria "originalidade" e, ao mesmo tempo, estabelece relações com demais textos que podem ser mais ou menos explicitadas. Segundo a estudiosa, existe uma "memória literária" que circula nos textos:

A literatura se escreve com a lembrança daquilo que é, daquilo que foi. Ela a exprime, movimentando sua memória e a inscrevendo nos textos por meio de um certo número de procedimentos de retomadas, de lembranças e de re-escrituras, cujo trabalho faz aparecer os intertextos. Ela mostra assim sua capacidade de se constituir em suma ou em biblioteca e de sugerir o imaginário que ela própria tem de si. (idem: 47)

Ao trabalhar com a retomada e reescritura de duas obras e permanecer por tanto tempo sem ser descoberto, Cendrars parece ter jogado com o conceito de "memória da literatura": provavelmente, os leitores não reconheceram o recorte, pois não tinham em sua "biblioteca" a leitura dos textos anteriores. Por outro lado, pensando na grande relação estabelecida com o romance de Le Rouge, talvez aquele que leu as duas obras precisasse muito mais que perceber o intertexto, mas confrontá-las para que se desvendasse o método de produção de Cendrars. Muitos anos depois de sua publicação, Documentaires trazia à tona a ideia de que uma obra poética precisa ser mais do que lida, mas profundamente analisada, pois reúne um grande número de recursos significativos. Foi assim que a obra de Cendrars permaneceu por anos provocando a sensação de novidade, chamando a atenção para o ato de escrita poética.

Tornando-se inegável um tipo de intertextualidade de Documentaires com outras duas obras, resta analisar como se estabeleceram as relações entre os textos. Samoyault (idem: 10) apresenta várias formas em que as práticas intertextuais podem realizar-se: a citação, a alusão, a referência, o pastiche, a paródia, o plágio e as colagens de várias espécies. Como já observado acima, de acordo com as relações percebidas entre os textos, podemos descartar as quatro primeiras formas, já que o trabalho de Cendrars é muito mais que uma citação, referência ou alusão dos textos de Le Rouge e Calmeyn. O poeta também não produziu um exercício de escrita imitando o estilo característico dos autores, tal qual preza o pastiche. Um suposto efeito paródico da escrita de Cendrars também pode 
facilmente ser questionado, pois, conforme afirma Samoyault (2008), a transformação ou a deformação da obra precedente, almejada pela paródia, sempre tem uma ligação direta e evidente com a literatura já existente, de modo que o texto anterior precisa ser reconhecido: "o caráter comum do patrimônio parodiado permite a todos os leitores reconhecerem facilmente o hipotexto e perceberem o efeito paródico" (idem: 54). Ora, o fato dos textos pré-existentes não terem sido reconhecidos anulam a possibilidade de uma paródia.

Documentaires aproxima-se muito da ideia do plágio, que, segundo Samoyault (idem: 51), constitui-se por uma espécie de apropriação total em que "o texto citado se funde com o texto que cita, abolindo assim a dupla presença" (idem: 52). É essa fusão entre as obras que talvez tenha dificultado a identificação do intertexto. Porém, fica claro que a intenção de Cendrars não era meramente plagiaria, sobretudo, pelas transformações que faz no texto, o modo como versifica e reorganiza os excertos, como analisado acima. Aliás, Samoyault prevê nas práticas plagiarias uma dinâmica propriamente literária quando a "cópia" é usada com fins lúdicos ou subversivos (idem: 51). Observa-se na obra de Cendrars essa dupla intenção, sobretudo, pela sua atitude de vanguardista que procurava experimentar as mais variadas práticas poéticas possíveis e "esticar" os limites do gênero, tal qual fez em seus Dix-neuf Poèmes Élastiques (1914).

A colagem também é uma prática intertextual que pode caracterizar muito bem as "fotografias verbais" de Cendrars. O termo veio da pintura e, durante as vanguardas, consistia na inclusão de fragmentos da realidade - como figuras de revistas, páginas de jornal, selos, dentre outros materiais - na obra, "forçando desta maneira o leitor ou observador de arte a considerar a interação entre a mensagem ou material preexistente e a nova composição artística de que resulta o excerto" (Perloff 1993: 21). Segundo Samoyault (idem: 36), nesses casos, a colagem marca exatamente o empréstimo do material inserido, exibindo sua procedência não artística e rompendo as fronteiras entre a arte e a vida. O caso da colagem de Documentaires, porém, absorve de tal forma o texto pré-existente que não marca mais sua heterogeneidade. Além disso, apesar de Au Congo Belge não ser um texto literário mas um relato de viagens, Le Mistérieux Docteur Cornélius já é uma obra literária e não algo que está fora do universo artístico. A "fotografia verbal" de Cendrars tinha o intuito 
de reescrever e recriar os textos pré-existentes. Esse tipo de colagem também se enquadra nos estudos de Samoyault:

\footnotetext{
Trata-se menos, como era o caso em pintura, de colar a vida na arte do que transformar profundamente o texto do outro, deslocando-o, oferecendo-lhe um novo contexto e de inscrever, por sua vez, seu próprio texto em relação. Além da simples questão terminológica, julgamos ainda que a questão das retomadas e dos empréstimos não atua unicamente sobre transferências das linguagens, mas sobre as consequências desse movimento. (Samoyault 2008: 38)
}

Como já dito, Cendrars anunciou que Documentaires iniciava um novo "gênero na literatura" (Cendrars 2006: 384), justamente por seu procedimento das "fotografias verbais" que se tratava também da colagem e reescrita sobretudo da obra de Le Rouge, com a inserção de excertos de Au Congo Belge. Se a vanguarda queria que o processo de escrita poética fosse autônomo, de modo que cada obra poderia romper com a tradição e criar suas próprias leis, as "fotografias verbais" inventam seu próprio método de criação: tomar excertos de textos de outros gêneros e transformá-los em poesia. Esse ato vai além do trabalho de reescrita e mostra outra visão da vanguarda, a de que a poesia reside em todas as coisas, inclusive nos textos em prosa. Nesse sentido, é muito interessante como trechos inteiros dos textos colados transformam-se em linguagem poética com pouquíssimas mudanças - vide o exemplo analisado acima do excerto retirado de Au Congo Belge.

Além de se aproximar da colagem, Documentaires também se vale de outro procedimento inovador para a literatura do início do século XX: a montagem. Apesar de o termo ter surgido com o cinema - e se reforçado com os estudos de Sergei Eisenstein -, pode-se dizer que a montagem possui fortes relações com a colagem. Muitas vezes, os dois termos são considerados sinônimos, porém, é preciso dizer que a montagem, em literatura, distinguiu-se pelo "movimento que caracteriza uma 'sucessão de episódios individuais paralelos e isolados', como se fosse a sucessão de episódios de fotogramas cinematográficos" (Damião 2007: 191).

Se Cendrars fala de "fotografias verbais", seu trabalho nesta obra, assim, pode ser considerado uma montagem dos textos de Calmeyn e, sobretudo, de Le Rouge, já que as imagens "captadas no filme fotográfico" podem também ser fotogramas do cinema. Como se estivesse fazendo uma produção cinematográfica, o poeta faz várias fotografias dos 
textos pré-existentes, rearranja e reedita as imagens captadas, para por fim, projetá-las sobre seu novo texto. Segundo Henri Béhar, "il ne fait pas de doute que Kodak est un film composé, et pas seulement un assemblage hétéroclite" (Béhar 1988: 175) [[...] não há dúvidas de que Kodak é um filme elaborado, e não somente uma colcha de retalhos]. Além disso, a adaptação de Cendrars, também transforma o gênero da obra inicial mais usada, a de Le Rouge: de romance para um documentário poético, tal qual o próprio título da obra sugere.

Eis, nessa obra, os vestígios da aproximação do poeta ao cinema. No período de 1921 a 1924, ele havia se engajado em produções cinematográficas com Abel Gance e participou da produção de La Roue e J'Accuse. Posteriormente, trabalhou na Itália para a empresa de produção cinematográfica Rinascimento e produziu La Venera Nera. Além disso, o poeta participou da produção de documentários, descreveu cenários, fez adaptações, escreveu diálogos e sinopses, dentre outros trabalhos para o cinema. Apesar de seu insucesso no ramo, conforme descreve Henri Béhar, toda experiência de Cendrars no cinema teria influenciado os recursos da montagem empregada em Documentaires:

Au témoignage d'Abel Gance, Cendrars se montrait désemparé par la technique cinématographique, il en avait du moins retenu les grandes lois du montage, comme le prouverait l'étude d'un scénario exactement contemporain de Kodak [...] où sont utilisés les variations scalaires d'objectif (du plan panoramique au très gros plan), les diaphragmes et les caches, avec en particulier la fermeture à l'iris, les mouvements de caméra (plongée, contre-plongée, travelling), les variations de vitesse (ralenti, accéléré, retour en arrière) et les techniques d'enchaînement (fondu, réimpression); où enfin passe, en deuxième plan, Le Rouge jouant le rôle d'un détective. (ibidem)

[Segundo o testemunho de Abel Gance, se Cendrars se mostrava desconcertado com a técnica cinematográfica, ele ao menos reteve as grandes leis da montagem, como provaria o estudo de um argumento exatamente contemporâneo de Kodak [...] onde são utilizadas as variações escalares de objetivo (do plano panorâmico ao plano detalhe), os diafragmas e os mattes, em particular o ajustamento da íris da lente e os movimentos da câmera (plongée ou câmera alta, contra-plongée ou câmera baixa, travelling), variações de velocidade (câmera lenta, câmera rápida, flashback) e as técnicas de corte (fusão, sobreposição); onde, enfim, passa, em segundo plano, Le Rouge encenando o papel de um detetive]. 
Além da montagem que reorganizou e recriou o romance de Le Rouge, acrescentando trechos de Au Congo Belge à trama, os textos de Cendrars aproximam-se muito das técnicas de filmagem, como afirmou acima Béhar (1988). O poema que abre a obra, "Roof-garden", que faz parte do sexto episódio de Le Mistérieux Docteur Cornélius, revela um modo narrativo muito semelhante ao da filmagem do cinema:

Des bosquets s'épanouissaient

Des pelouses d'un vert tendre

Une source vive jaillit entre les rhododendrons et les de camélias

Le soir

Les waiters graves comme des diplomates vêtus de blanc se penchent sur le gouffre de la ville

Et les massifs s'éclairent d'un million de petites lampes versicolores

Je crois que Madame murmura le jeune homme d'une voix vibrante de passion contenue Je crois que nous serons admirablement ici

Et d'un large geste il montrait la large mer

Le va-et-vient

Les fanoaux des navires géants

Le géante statue de la Liberté

Et l'énorme panorama de la ville coupée de ténèbres perpendiculaires et de lumières crues

Le vieux savant et les deux milliardaires sont seuls sur la terrasse

Magnifique jardin

Massifs de fleurs

Ciel étoilé

Les trois vieillards demeurent silencieux prêtent l'oreille au bruit des rires et des voix joyeuses qui [montrent des fenêtres illuminés

Et à la chanson murmurée de la mer qui s'enchaîne au gramophone. (Cendrars 2006: 147-148)

[Bosques floresceram

Gramados de um verde suave

Uma viva fonte jorra entre rododendros e camélias

Noite

Garçons sérios como diplomatas vestidos de branco debruçam-se no abismo da cidade

E os maciços se acendem com um milhão de pequenas lâmpadas versicolores

Eu acredito que Madame murmurou para o jovem com uma voz vibrante de paixão contida

Eu acredito que nós estaremos admiravelmente aqui

E com um gesto largo, ele mostrava o extenso mar 
O vai e vem

Os faróis dos navios gigantes

A gigante estátua Liberdade

E o enorme panorama da cidade cortada por trevas perpendiculares e por luzes de cruas

O velho cientista e os dois bilionários estão sozinhos no terraço

Jardim magnífico

Canteiros de flores

Céu estrelado

Os três velhos permanecem em silêncio para ouvir o som de risadas e vozes felizes que mostram as [janelas iluminadas

E a canção murmurada do mar que se liga ao gramofone].

Nesse poema, é possível perceber como Cendrars aproxima-se da noção de enquadramento, advindo da linguagem cinematográfica. Em um poema prosaico, o leitor, como um expectador de um filme, vai sendo levado a perceber a ambientação do espaço onde a primeira parte do livro vai ser passar: na América do Norte, entre a riqueza e modernidade, em contraste com as lindas paisagens naturais. Para mostrar essa contraposição, o poeta indica de várias formas que haverá um "vai e vem" - "Le va-et-vient" - de imagens, mostrando uma festa dentro de um alto edifício, cheia dos artifícios da modernidade, e as cenas das paisagens naturais fora do prédio. Primeiramente, semelhante a um plano aberto, a paisagem dos bosques floridos parece ser "gravada" da janela do salão onde se passa a cena. Com um corte, o olhar da câmera se volta para dentro do espaço onde uma festa de requinte acontece. O plano geral recorre o salão, mostrando os garçons bem vestidos, e enquadra uma senhora cochichando no ouvido de um jovem. De repente, o personagem aponta para a janela e eis que o "foco da câmera" sai do espaço interno para o externo. Faz-se um panorama do mar, dos navios, da cidade e da Estátua da Liberdade, situando assim o espaço em Nova lorque. Mais uma vez, percebe-se que a "câmera" grava de dentro do salão, pois capta ainda dois personagens conversando no terraço e, ao mesmo tempo, o jardim lá embaixo e o céu estrelado. Nessa descrição do espaço, há uma coesão entre o mundo natural e o moderno pela iluminação da cena: as luzes de "um milhão de lâmpadas", dos "faróis dos navios", da iluminação "crua" da cidade e das janelas do salão se misturam com o "céu estrelado" e com as cores vivas da vegetação. Todas essas luzes criam 
o efeito de exaltação para essa cena, o mesmo, de certa forma, de toda a obra. A coesão entre o moderno e o natural finaliza o poema pela forma que o som do mar funde-se com o do gramofone: "Et à la chanson murmurée de la mer qui s'enchaîne au gramophone".

Desse modo, o aspecto narrativo assumido pelo poema assemelha-se ao modo estético com que a montagem cinematográfica conta histórias por meio de imagens. Cendrars não poderia ter deixado de participar da história da nova arte que se instaurava, o cinema, e tampouco teria deixado de colher nas fontes cinematográficas inspiração para seu trabalho como poeta, já que toda a obra do escritor foi um retrato do mundo moderno e de suas inovações.

O poeta, que já tinha buscado em várias técnicas diferentes a inovação do gênero poético, encontra no processo de reescrita uma nova forma de inovar seus métodos de produção poética. Valendo-se das potencialidades da fotografia e do cinema, Cendrars recria o texto Le Mistérieux Docteur Cornélius, inserindo trechos de Au Congo Belge, por meio das "fotografias verbais". Tal exercício de recriação rompe, assim, as fronteiras entre a literatura e as artes visuais - o cinema e a fotografia - criando um "Documentário poético" sobre os contrastes entre o mundo moderno e o natural na América do Norte e na África. É nessa pluralidade de técnicas e assimilações de outras artes e gêneros que Documentaires se insere no contexto vanguardista de experimentação, de renovação da poesia, criando uma obra que possui suas próprias formas e técnicas de escrita.

\section{NOTA}

\footnotetext{
${ }^{1}$ Muitas obras de Blaise Cendrars criaram grandes controvérsias no meio literário mundial. O livro de poemas em língua russa, La Légende de Novgorode, por exemplo, permaneceu desaparecido por muitos anos e chegou a ser considerado mero fruto da imaginação de Cendrars. Em 1995, surge um exemplar do livro, porém sua autenticidade continua sendo questionada por muitos estudiosos. Outro exemplo é La Prose du Transsibérien et de la Petite Jehanne de France (1913), chamada de "Le premier livre simultané", que foi acusada de plágio pelo poeta Henri-Martin e que também gerou contestações dos futuristas que pregavam em seus manifestos o princípio da simultaneidade e, portanto, chamavam para si a autoria do conceito.
} 


\section{Bibliografia}

Béhar, Henri (1988), “Débris, collage et invention poétique”, Littéruptures, Lausanne, L'Âge d'Homme, 169-181.

Bürger, Peter (1993), Teoria da Vanguarda, tradução de Ernesto Sampaio, Lisboa, Vega.

Calmeyn, Maurice (1912), Au Congo Belge. Chasses à l'éléphant, les indigènes, l'administration, Bruxelas, Bruxelles.

Cendrars, Blaise (1945). Homme Froudroyé, Paris, Édtions Denoël.

-- (1987), "La Prose du Transsibérien et de la Petite Jehanne de France", in Genèse et dossier d'une polémique. La Prose du Transsibérien et de la Petite Jehane de France, Blaise CendrarsSonia Delaunay, novembre-décembre 1912-juin 1914, Paris, Lettres Modernes, 99-100.

-- (2006), Du Monde Entier au Cœur du Monde. Poésies complètes, Paris, Gallimard.

Compagnon, Antoine (1996), O Trabalho da Citação, tradução de Cleonice P. B. Mourão, Belo Horizonte, Editora UFMG.

-- (2003), Os Cinco Paradoxos da Modernidade, tradução de Cleonice P. B. Mourão, Consuelo F. Santiago, Eunice D. Galéry, Belo Horizonte, Editora UFMG.

Damião, Carla Milani (2007), “Montagem e Avantgarde”, in Leituras de Walter Benjamin, São Paulo, FAPESP, Annablume, 189-191.

Le Rouge, Gustave (1992), Le Mystérieux Docteur Cornélius, vol. 1, Paris, Robert Laffont.

Perloff, Marjorie (1993). O Momento Futurista. Avant-guarde, avant-guerre, e a linguagem da ruptura, tradução de Sebastião Uchoa Leite, São Paulo, Editora da Universidade de São Paulo.

Samoyault, Tiphaine (2008), A Intextextualidade, tradução de Sandra Nitrini, São Paulo, Aderaldo \& Rothschild.

Weisgerber, Jean. (ed.) (1986), Les avant-gardes littéraires au XXe siècle. Théorie, Budapeste, Akadémiai Kiadó, 2o vol. 
Natalia Aparecida Bisio de Araujo é doutoranda em Estudos Literários pela Universidade Estadual Paulista - UNESP - com o projeto As Relações Estéticas entre Blaise Cendrars, Oswald de Andrade e Tarsila do Amaral no Modernismo Brasileiro financiado pela CAPES. Mestre em Estudos Literários pela mesma instituição, com a dissertação intitulada $A$ Obra Poética de Blaise Cendrars. Uma Expressão das Vanguardas. 